\title{
Chapter 3 \\ Pontificia Universidad Católica Support \\ for the School System During the Covid-19 \\ Pandemic in Chile
}

\author{
Ernesto Treviño, Magdalena Claro, and Lorena Medina
}

\begin{abstract}
This chapter presents the case of the Pontificia Universidad Católica de Chile in supporting the school system during the Covid-19 pandemic. It shows how supporting individual faculty initiatives as well as interinstitutional collaborations and participating in and supporting specific policies shaped a complex array of support for a highly atomized school system because of its market-driven arrangements. The case study also shows that, beyond individual initiatives, collaboration among Chilean universities was key for rapidly responding to the emerging needs of schools.
\end{abstract}

\subsection{Introduction}

The role that universities take in supporting schools during the Covid-19 pandemic is highly dependent on context. This chapter focuses on the role of the Pontificia Universidad Católica de Chile (PUC) in supporting educational continuity in Chile through both a partnership with Universidad de Chile, to coordinate university proposals to advise the government through the Mesa Social Covid-19 (Covid-19 Social Roundtable), and institutional initiatives.

This chapter presents these two interlinked initiatives for education continuity and is organized into five sections. First, it presents the context of the pandemic in Chile, which is critical to understand this case. The second section presents PUC's mission and role in society as a framework to explain the initiatives to support school continuity. The third focuses on the Joint Venture between PUC and Universidad de Chile to lead a collaborative effort to support school continuity. The fourth section describes and explains, in a timeline format, the different initiatives to support school continuity at PUC. Lastly, the fifth section delves into the main concepts that help to delineate institutional efforts to support school continuity.

E. Treviño $(\bowtie) \cdot$ M. Claro $\cdot$ L. Medina

Faculty of Education, Pontificia Universidad Católica de Chile, Santiago, Chile

e-mail: ernesto.trevino@uc.cl 


\subsection{Chilean Context During Covid-19}

The Chilean government asked academic institutions for assistance to create an advisory committee known as "Mesa Social Covid-19," which began its operations on March 22, 2020. The academic committee of the Mesa Social is led by the presidents of the Pontificia Universidad Católica (PUC) and the University of Chile (UCh) and aims to promote evidence-based decision-making within the government. The Mesa Social focused its attention on different issues starting with public health, epidemiology, and mental health, followed by education and the economy.

As noted, the work of the Mesa Social initially focused on public health issues. However, by the first days of April 2020, the dean of the Faculty of Education proposed to the authorities (Highest Direction or Dirección Superior, in Spanish) of PUC to add a specific multi-disciplinary group on education, healthcare, and the economy to the Mesa Social. This recommendation was accepted and immediately implemented through collaborative work between PUC and Universidad de Chile. The newly established group worked on proposals and specific guidelines to help the school system on the necessary measures to provide socioemotional and academic support to students and their families.

The Chilean educational context has particularities that are important to consider when examining universities' joint efforts to support school continuity. First, it is one of the most privatized school systems in the world, with two-thirds of the enrollment attending private-subsidized schools. These private-subsidized schools, funded with public resources, are primarily schools owned by one individual, not part of a larger network of schools, nor receiving pedagogical support directly from educational authorities. Moreover, since privatization and competition are also central features in the higher education sector, therefore collaboration among leading institutions is less common due to the existing incentives of the system. Additionally, Chile is a national unitarian country, whereas the Ministry of Education, a national government entity, has direct influence over all the schools receiving public funds in the country. These three contextual elements are crucial for understanding the process of supporting schools during the pandemic in Chile, and their obvious fragmentation, which aims at covering a wide range of schools in the initiatives. Finally, it is worth mentioning that several protests had already disrupted schooling between October and December 2019, especially for students in urban areas near places of gathering for protesting. Therefore, the challenges for school continuity in Chile combined previous social unrest with the effects of the pandemic.

\subsection{PUC's Mission and Role in Society}

Institutionally, PUC's mission includes key concepts that serve as guidelines to deal with the pandemic. Before the arrival of Covid-19, PUC has prioritized public commitment to transfer knowledge and contribute to the improvement of quality of life. 
Within this framework, the Faculty of Education had already structured its development around the concepts of educational justice, pedagogies of the practice, and digital educational practices, always considering the link between research and practices as a central part of its public commitment.

During the pandemic, PUC's work on school continuity was guided by several principles. First, there is a growing sentiment that the work at the university and faculty level requires a deeper and stronger connection to the daily challenges faced by schools. Second, this connectedness requires a more holistic and interdisciplinary focus to promote students' well-being in schools. This means re-thinking the logic of educational research to take into consideration different aspects of wellbeing of the students alongside academic achievement. Such change entails aiming at a more profound comprehension of the personal and social situations of children attending school to craft teaching strategies that promote their holistic development. Third, the challenge of supporting schools requires collaboration rather than competition among universities. For instance, although PUC is a leading research university in Chile, it has a limited scope to cover the needs of the school system just like other institutions. Accordingly, PUC and Universidad de Chile decided to join forces under the umbrella of the Mesa Social to coordinate efforts to support education continuity and invite academics from various universities in the country to contribute according to their different specializations.

\subsection{Collaboration Venue: Joint Venture of Leading Universities}

As previously mentioned, PUC joined forces with the Universidad de Chile (UCh) to provide academic advice to the government on pandemic decision-making. The PUC is a private institution whereas the UCh is a public university, and both are in the capital city of Santiago. It is worth noting that these two universities are the most prestigious, oldest, and selective in Chile. Both are research-oriented institutions, and their graduates usually take leadership positions nationally. They also form part of the University Presidents' Council, an entity created in 1954 by the Chilean government to support the development of the country via a network of public and private-traditional universities which receive financial support from the government (Consejo de Rectores, 2020).

The joint venture to address the challenges of the pandemic consisted of a strategic plan of three phases within the framework of the Mesa Social. First, PUC and UCh presented proposals to the Mesa Social on school continuity, starting with a report with guidelines and recommendations for policy and practice with short-, mid-, and long-term perspectives entitled "Proposals for Education - Inter-university report of the Social Table 3B Covid-19" (Propuestas Educación -Trabajo Interuniversitario Mesa Social 3B Covid-19) (Mesa Social, 2020c). Both universities convened a steering committee to coordinate the preparation of this document 
during March, when the government planned vacations during the two last weeks of April and stated that students would be back in schools by April 27. The recommendations prepared for school continuity were published on April 24 and delivered to the Minister of Education. At the time of this presentation, the government had already announced that there was not a fixed date to return to school because such a decision was dependent upon the progression of the pandemic.

The proposals in the document had three aims. First, it recommended measures to provide emotional support for students affected by post-traumatic stress with consideration to the degree of intensity. Second, it provided guidelines to develop curriculum adjustments and suggestions to create remote education strategies. Third, the document provided guidelines for policies in terms of curriculum adjustments, flexibilization of funding, cancellation or diminishing of assessments, and high stakes accountability measures.

In the second phase, the steering committee convened experts from different universities to develop guidelines and pedagogical strategies to work in the prioritized curriculum for 2020 and 2021 (two different school years), proposed by the Ministry of Education through by June 20, 2020 (MINEDUC, 2020). More than 90 academics from PUC, UCh, and other universities, alongside schoolteachers, developed specific and adaptive guidelines to implement the streamlined curriculum, based on principles such as prioritization, flexibility, integration, and fostering student agency. More specifically, the document provides recommendations to follow learning pathways in Arts, Science, Physical Education, History, Geography, Social Sciences, English, Language (Spanish), and Mathematics (Mesa Social, 2020a). In addition, the recommendations consider three different connectivity situations: (a) students and teachers with access to the Internet for synchronous classes, (b) students and teachers with limited access to Internet that may need a-synchronous classes, and (c) students without access to Internet, in which case teachers and schools are organizing the delivery of printed educational materials (Mesa Social, 2020a). The guidelines follow a modular approach that allows for high flexibility in their usage depending on the different school contexts and needs. As such, these recommendations are intended to be useful beyond the emergency of this pandemic. The document was entitled "Pedagogies of the proximity: Learning in times of crisis," available in Spanish as Didácticas de la Proximidad: Aprendiendo en tiempos de crisis (Mesa social, 2020a).

Also, academics from PUC, the UCh, and Pontifical Catholic University of Valparaiso created a series of recommendations to support school leaders entitled "School leadership: Learning in times of crisis"-in Spanish, Liderazgo Escolar: Aprendiendo en tiempos de crisis (Mesa Social, 2020b). These recommendations focus on three different moments for school continuity: (a) leadership during the pandemic and school closures; (b) leadership focused on teaching and learning during the pandemic; and (c) preparing the schools for returning to in person education. Connectedness, collaboration, contention, training, and trust are the key concepts behind the leadership guidelines (Mesa Social, 2020b).

Both documents with recommendations for teaching and leadership were presented on July 23 in an open webinar with the presence of the presidents and 
authorities of PUC and UCh, the leaders of the Steering Committee, academics, as well as two classroom teachers and school principals. Nearly 10,000 people viewed the presentation at some point, and more than 2000 people stayed for the whole webinar. Furthermore, by the end of July more than 1000 people had downloaded the document on teaching, and nearly 300 downloaded the guidelines for leadership.

\subsection{PUC's Efforts to Support the School System: A Timeline}

As stated before, efforts to support school continuity started within the framework of the Mesa Social with the launch of proposals for education on April 24, 2020 (Mesa Social, 2020c). Since the university has supported school continuity in both collaborative and institutional initiatives, this section provides a timeline of the specific actions and a brief explanation of their content.

In terms of the social and political situation, these proposals helped to delineate the significance and long-lasting adverse effects that the pandemic could have if authorities and stakeholders in the education system did not implement adjustments to the education services.

After the release of the report on proposals for education, PUC continued developing institutional efforts to support school continuity. Specifically, PUC organized 12 webinars, via its Center for Educational Justice with the Faculty of Education, on topics ranging from digital teaching strategies to teaching math, language, science, as well as project-based learning and curricular prioritization. These webinars started in May and continued through September. This initiative was a response to the decentralized organization of the school system and the delay in support responses from the national authorities due to the uncertainty introduced by the pandemic. In this way, it was possible to offer ample national coverage to those schools and teachers in need of support. Nearly 5000 teachers from schools from across the country had participated in the webinars until the end of June. This has been a highly flexible support strategy to adapt to the needs of the school system.

The System of Practices, a program in PUC's Faculty of Education for students in initial teacher training programs, was one of the main direct connections to the school system prior to Covid-19. Student teaching is a requirement for graduation, and the pandemic opened an opportunity to reframe the logic of the teaching practices to support school continuity. The main adaptations to the System of Practices to address challenges caused by the pandemic consisted of:

(a) A series of online training for teaching teams in kindergartens through audio presentations, teaching guides, and some online synchronic sessions to explain the contents

(b) Workshops implemented by student-teachers on topics related to teaching during the pandemic for schools with connectivity limitations

(c) Short videos on the implementation of curricular contents for each discipline and school grade available at each school 
(d) Audio recommendations on how to work with families and teaching teams in the school community during the pandemic

(e) Online classes with the participation of student-teachers in schools implementing virtual education during the pandemic

(f) Coaching to groups of students in the classroom in several schools that required differentiated support

(g) The design and distribution of educational lessons to families to support school continuity

(h) Design and dissemination of learning resources for remote development of skills and knowledge for each curriculum discipline and school grade

These initiatives have supported 60 schools (31\% public, $30 \%$ private-subsidized, and $39 \%$ private schools) that have been connected to the Faculty of Education System of Practices before the pandemic. Lastly, the System of Practices of the Faculty of Education at PUC has also contributed to school continuity through the sharing of electronic bulletins that contain recommendations for education and surveys to collect information regarding school needs. These latter actions were implemented in collaboration with the Observatory of Digital Education Practices (OPED, in Spanish Observatorio de Prácticas Educativas Digitales).

The Faculty of Education of PUC also joined a governmental program designed and implemented by the Ministry of Education called "Network of Coaches for Chile"-in Spanish Red de Tutores para Chile. This initiative offers students in initial teacher training programs (student-teachers) opportunities to develop inclassroom practices required by their initial teacher training programs through virtual education. At the same time, such programs allow students from different universities across the country to provide coaching or tutoring to students in different schools to support classroom teachers. This approach can offer more individualized attention and, especially, a method for self-study and self-learning that can have long-lasting effects developing independent studying and learning skills among students.

In terms of school continuity, the Center for Educational Transformation (CENTRE UC), which oversees providing in-service teacher training and coaching to teachers and school communities, has changed all its programs to be offered virtually, including those involving coaching and feedback. Also, CENTRE has contributed to supporting school continuity by participating in the Group of Innovation on Early Childhood Education from the Ministry of Education which started in July 2020 to develop policy guidelines to face the pandemic in this educational level from 2020 and beyond.

Finally, the Agency for International Cooperation and Development of Chile (AGCID) asked PUC to design and implement a series of webinars to support the continuity of education in other South American countries during the months of September through November. These seminars focused on (a) continuity of education during the pandemic; (b) challenges of the pandemic for pre-service and inservice teacher training; (c) how to prioritize the curriculum to promote development 
and learning among students; and (d) current situation of the education systems and challenges for an after-pandemic world.

\subsection{Concepts that Frame Efforts to Support School Continuity at PUC}

The conceptual elements that can explain PUC's commitment to supporting school continuity can be classified into institutional concepts aligned to PUC's mission and emerging concepts necessary to expand the scope of such a mission in the face of the pandemic.

Five concepts were already present in the PUC and its Faculty of Education when the pandemic arrived, which allowed the institution to frame the challenge of school continuity. First, public commitment is part of the PUC's mission, a concept that entails strengthening links with society to contribute to solving social challenges. The second concept is the link between research and practice, which has been developed by the Center of Studies of Educational Policies and Practices since it was launched in 2010. Educational justice is the third concept, in which the Center for Advanced Studies on Educational Justice of PUC has been researching aspects of policy and practice that influence the possibility of reaching more justice and equality in terms of supporting the most disadvantaged groups of students and critically questioning social expectations based on stereotypes or prejudices since 2017. Fourth, the concept regarding pedagogies of the practice has been used to structure initial and continuous teacher training in the Faculty of Education. Finally, digital education practices were a fifth concept that was already present in the Faculty of Education of PUC. In fact, the Faculty created an Observatory of Educational Digital Practices in 2017 with the aim of supporting academics within the Faculty to incorporate technology in their own teaching and develop student-teachers' digital skills and knowledge. The observatory has also participated in several research projects on remote education in Chile, and most importantly, it has been an invaluable asset to help PUC and the Faculty of Education face the challenge of supporting school continuity. Without this institutional arrangement, it would have been more difficult to respond to the needs of school continuity. Therefore, the combination of having this institutional arrangement and the knowledge accumulated through research has allowed PUC to design responses for school continuity that include digital strategies.

These five principles have allowed training programs to be better designed with solid theoretical bases and an intensive system of practices and coaching to support students in initial teacher training programs in learning how to implement classes that are aligned with evidence and are successful in promoting student learning.

The concepts that PUC had cultivated as an institution before the pandemic were of great help in framing the challenge of school continuity for the wider education community. However, they were insufficient to genuinely respond to the needs 
posed by the pandemic. At the institutional level, there are two elements that have been magnified due to the pandemic: collaboration and connectedness.

In this new context, the pandemic has shown us that the magnitude of the challenges is well beyond the scope and capacity of one institution. The notion of collaboration to solve problems has emerged as a critical element even in an education system traditionally marked by high levels of market competition among educational institutions. In this sense, having the public and the private leading universities in Chile collaborating instead of competing represents a profound change in perspective. There has also been a newly applied element of connectedness with the wider school system. As such, the intentional reflection at the Faculty of Education at PUC has focused on redefining the ways in which PUC connects to the school system. On one hand, the conversations among academics have led to initial definitions of relevant research that intends to improve schools, especially learning and development opportunities for the most disadvantaged children. This dialogue has led to an agreement between the Faculty of Education at PUC and the Local Service of Public Education Gabriela Mistral, which is primarily a school district of public schools in a territory serving a low SES population in the surroundings of the PUC San Joaquín Campus. This relationship was formed to support schools with studentteachers doing their practical training and offer different levels of support to the schools.

At the research level, the element of connectedness has been bidirectional. From PUC to the school system, research conducted must consider the evident needs of the population under study, the contextual and bureaucratic demands that schools face, and the requirements of the policy. The other direction of connectedness refers to a more fluid, horizontal, and holistic dialogue between universities and the school system. Consequently, future research projects may evolve toward including more collaboration with school actors in the design, implementation, and production of research results with schools. Although this is not the only way to address connectedness in research, it is a working definition presently used at the university. During a webinar on July 23, the president of PUC pointed out that collaboration needs to lead to connectedness in multidirectional dialogues between universities, school system, academics, teachers, and principals along the country as a way to overcome the crisis and build durable ties for the improvement of education.

Beyond the concepts of connectedness and collaboration, during the social protests at the end of 2019 and throughout 2020, two other elements emerged as concerns in relation to the role of the university to support the school system.

First, the element of holistic well-being among children and school communities regarding the school system was exposed as a primary concern. Chile is one of the most unequal countries of the OECD, a feature that can negatively impact a child's mental health because of the effects of marginalization (OECD, 2020; Treviño, Villalobos \& Castillo, 2020). Chile also has high levels of child abuse and maltreatment, which must be addressed in the school system since the national health system offers limited support for mental health conditions (Treviño, Villalobos \& Castillo, 2020). The interrelation between the cognitive, social, emotional, and physical elements of child development (Shonkoff \& Phillips, 2000) has been 
routinely neglected by the school system, whereas incentives and accountability of schools is primarily based on the school average test score results as stated in both national laws for the quality of education (No. 20.529) and the preferential voucher regulation (No. 20.248) in Chile.

Another emergent element is evidence-based guidance for schools from universities. In this context, evidence-based guidance means providing recommendations to overcome the challenges of the pandemic utilizing accumulated knowledge. This required universities to adapt research results, analyzing the existing literature on education during emergencies, and compiling recommendations with the best professional judgment to collectively face an unprecedented situation. The collaboration between academics, teachers, and principals was key in shaping such recommendations. It is important to also note that this guidance must not be misinterpreted as a straightforward prescription. The range of specific situations happening in schools across the country is difficult to predict, and therefore evidence-based guidance aims at providing recommendations that can be adapted and flexible to form a measured response to local needs.

This approach to guidance is especially necessary given the geographic context of Chile. The continental part of the country is long and thin with more than 6000 kilometers of seacoast to the west and guarded by the Cordillera de Los Andes to the east. The maximum width of this long territory is 360 kilometers from the border in Los Andes mountains to the sea, and its minimum width is 17 kilometers. Furthermore, the geography of Chile also includes several islands in the Pacific and Antarctic oceans.

The elements described above define the rationale of PUC's efforts to effectively gather evidence, provide guidelines for the school system, and inform policymaking to ultimately provide locally legitimate support to teachers and schools.

Lastly, it is noteworthy that PUC structured these efforts without providing additional resources to support them. Instead, different actors within the university reorganized their time and resources to serve the needs of the school system. The president of PUC and the dean of the Faculty of Education provided moral, but not financial, support.

\subsection{Conclusion}

The Covid-19 pandemic has impacted the social and economic life of vast proportions of the population around the globe. And while the effects of the pandemic on school continuity have been adverse, higher education institutions have been attempting to contribute positively to the effort of continuity in various ways.

In Chile, the establishment of the Mesa Social to advise the government with the participation of the presidents of both PUC and UCh represented an important milestone in the process of supporting school continuity. Originally thought as a group to provide advice on health issues, the Mesa Social included a chapter on education 
thanks to the commitment of both the Faculty of Education and the highest authorities of PUC.

There are several concepts that were already central to the mission of PUC that were useful guidelines to frame the efforts of school continuity: public commitment of the university to its surrounding environment, the link between research and practice, the notion of educational justice, the development of digital education practices, and pedagogies of the practice. On the other hand, collaboration and connectedness are newly incorporated concepts that emerged as key conceptual orientations for future work with the school system. The practice of collaboration has resulted in growth in the capacity of universities and schools to work together even in a highly privatized and competitive educational environment, in which these educational institutions typically compete for students and funds. Moreover, due to increased connectedness, there has been an expansion of the capacity of universities and schools to mutually learn how to address educational, pedagogical, or organizational issues that may impede schools to fully achieve their mission.

This pandemic has already provided several enduring lessons for Chile, considered one of the most advanced in education and most developed in the Latin American region. The pandemic first exposed how profound educational inequalities are in the Chilean school system and the disparities in access to the Internet between the advantaged and disadvantaged populations.

The shortcomings of the existing regulatory framework, which focuses on highstakes testing, privatization, and universal voucher funding, were made evident by the extraordinary situation created by the pandemic. Even despite the obvious difficulties of conducting examinations during Covid-19, the national assessment system insisted on applying the national high stakes tests, a decision which was finally reversed by July.

School communities have also been leading impressive efforts to deliver educational services to their students at a time when authorities focused on short-term issues without a systemic and coordinated plan that allowed schools to adapt to this new environment. However, it is difficult to estimate the magnitude of these efforts in the school system.

Within the Faculty of Education at PUC, there is a shared notion that several of these noted changes in the school system and the Faculty itself should be enduring to continue to best support the school system and teachers to shape opportunities for students, with a focus on educational justice, to develop the twenty-first-century skills required to participate in a post-pandemic world.

Although the efforts from authorities and universities to ensure school continuity have been substantial, facing the pandemic has been a challenge in Chile due to inequalities in the access to Internet in the country. Nearly $44 \%$ of the population does not have household Internet connection, and 13\% of the population does not have any type of connection. Furthermore, the digital gap is significant in the case of low-income households and the elderly (Subtel, 2017). For that reason, the recommendations were designed with this context in mind. 
At the moment of finishing this chapter, April 2021, the evolution of the pandemic in Chile and the world is far from being under control. The Ministry of Education in Chile has insisted prioritizing in-person classes over virtual or hybrid models. The ministry announced an in-person beginning of the school year in March, subsequently changing this decision without a robust plan for considering the scenario of the pandemic disrupting school in 2021. Today universities are designing new strategies of support for schools in alignment with their aims toward initial and continuous teacher training, among other priorities.

\section{References}

Consejo de Rectores. (2020). Nuestra historia. https://www.consejoderectores.cl/historia. Retrieved on 27 July 2020.

Mesa Social. (2020a). Didácticas de la Proximidad: Aprendiendo en tiempos de crisis. http:// educacion.uc.cl/listado-de-noticias/1403-descarga-informes-de-propuestas-educacion-de-lamesa-social-covid-19

Mesa Social. (2020b). Liderazgo Escolar: Aprendiendo en tiempos de crisis. http://educacion. uc.cl/listado-de-noticias/1403-descarga-informes-de-propuestas-educacion-de-la-mesasocial-covid-19

Mesa Social. (2020c). Propuestas Educación. Trabajo Interuniversitario Mesa Social 3B Covid-19. http://ceppe.uc.cl/images/contenido/investigacion/Informes/informe-mesa-covid19uc-y-uchile.pdf

MINEDUC. (2020). Resolución Exenta No. 2765. June 20th, 2020.

OECD. (2020). OECD data: Income inequality. https://data.oecd.org/inequality/incomeinequality.htm

Shonkoff, J. P., \& Phillips, D. A. (2000). From neurons to neighborhoods: The science of early childhood development. National Academies Press.

Subtel. (2017). 44\% de los hogares del país no tiene conexión fija a Internet. Subsecretaría de Telecomunicaciones, Chile. https://www.subtel.gob. cl/44-de-los-hogares-del-pais-no-tiene-conexion-fija-a-internet/

Treviño, E., Villalobos, C., \& Castillo, C. (2020). La educación tras la COVID-19. Cuatro claves para la transformación de los sistemas educativos de Latinoamérica. In O. Granados (Ed.), La educación del mañana: ¿inercia o transformación? Consejo Asesor de la OEI. Organización de Estados Iberoamericanos. https://oei.int/publicaciones/la-educacion-del-manana-inercia-otransformacion. Accessed on 16 August 2021.

Ernesto Treviño is Director of the Center for Educational Transformation, Associate Professor, and Principal Investigator at the Center for Advanced Studies on Educational Justice at the Faculty of Education of the Catholic University of Chile. His research has focused on the connections between education policies and practices, with a perspective of equity and inclusion.

Magdalena Claro is the Director of the Center of Studies for Educational Policies and Practices and assistant professor at the Faculty of Education of the Catholic University of Chile. She has worked in national and international projects related to digital technologies in education, particularly in relation to the definition, evaluation, and development of students' digital skills. Her research is related to digital society and the new divides, teaching and learning in digital contexts and students' digital skills. 
Lorena Medina is an Associate Professor at the Faculty of Education of the Catholic University of Chile. She was the dean of the Faculty of Education during the 2014-2021 period. She was also the President of the National Council of Deans of Faculties of Education (CONFAUCE) in Chile for the period of 2019-2021. In January 2021 she founded the Latin American Network of Deans of Education, with the financial support of Siemens Stiftung, as the general coordinator for 2021. Her research has focused on the dialogic discourse analysis in educational contexts, literacy and semiotic initial development, teaching and learning of language, and conceptions and theories on learning specific contents in native language.

Open Access This chapter is licensed under the terms of the Creative Commons Attribution 4.0 International License (http://creativecommons.org/licenses/by/4.0/), which permits use, sharing, adaptation, distribution and reproduction in any medium or format, as long as you give appropriate credit to the original author(s) and the source, provide a link to the Creative Commons license and indicate if changes were made.

The images or other third party material in this chapter are included in the chapter's Creative Commons license, unless indicated otherwise in a credit line to the material. If material is not included in the chapter's Creative Commons license and your intended use is not permitted by statutory regulation or exceeds the permitted use, you will need to obtain permission directly from the copyright holder.

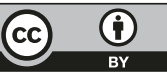

